\title{
Difference in Time Course of Modulation of Synaptic Transmission by Group II Versus Group III Metabotropic Glutamate Receptors in Region CA1 of the Hippocampus
}

\author{
Lisa M. Giocomo and Michael E. Hasselmo
}

\begin{abstract}
We investigated the time course of modulation of synaptic transmission by group II and group III metabotropic glutamate receptors in region CA1 of the hippocampus. In the presence of $50 \mu \mathrm{M}$ picrotoxin, pressure pulse application of $1 \mathrm{mM}$ glutamate resulted in a fast onset of suppression of synaptic transmission in stratum lacunosum moleculare and a slower onset of suppression in stratum radiatum, with both effects returning to baseline over the course of several minutes. Application of $50 \mu \mathrm{M}$ of the group II agonist (2R,4R)-APDC in stratum lacunosum moleculare resulted in the same fast onset of suppression while having no effect in stratum radiatum. Pressure pulse application of $100 \mu \mathrm{M}$ DL-AP4 in stratum lacunosum moleculare and stratum radiatum resulted in a much slower onset of suppression of synaptic transmission than (2R,4R)-APDC. Suppression by $(2 R, 4 R)-A P D C$ was accompanied by a rapid enhancement of paired pulse facilitation, indicative of a presynaptic mechanism. This demonstrates that activation of group II mGluRs in the hippocampus causes a fast onset of suppression in stratum lacunosum moleculare, while activation of group III mGluRs causes a slower onset of suppression. The difference in time course for group II vs. group III mGluRs suggests a different functional role, with group II playing a potential role in making synapses act as low pass filters. $\odot 2006$ Wiley-Liss, Inc.
\end{abstract}

KEY WORDS: hippocampus; metabotropic glutamate receptor; synaptic transmission; time course; CA1

\section{INTRODUCTION}

In addition to NMDA ( $N$-methyl-D-aspartate), AMPA ( $\alpha$-amino-3hydroxy-5-methyl-4-isoxazole-propionate), and kainate receptors, glutamate acts through G-protein coupled metabotropic glutamate receptors (mGluRs). The mGluRs consist of three known families, grouped according to their molecular structure and pharmacological profile (Conn and Pin, 1997, 2001; Shoepp et al., 1999). Group I mGluRs (mGlu1 and mGlu5) are coupled to phospholipase C and phosphoinositide hydrolysis and are primarily localized to postsynaptic zones (Conn and Pin, 1997; Shigemoto et al., 1997). Group II (mGlu2 and mGlu3) and Group III (mGlu4, mGlu6, mGlu7, and mGlu8) mGluRs are negatively coupled to adenylate cyclase thereby decreasing cAMP formation (Conn and Pin, 1997) and are localized on presynaptic elements (Shige-

Program in Neuroscience, Center for Memory and Brain, Boston University, Boston, Massachusetts

Grant sponsor: NIH; Grant number: MH60013, MH61492 and DA 16454 (CRCNS); Grant sponsor: NSF Science of Learning Center; Grant number: SBE 0354378.

*Correspondence to: Lisa Giocomo, Center for Memory and Brain, Boston University, 2 Cummington Street, Boston MA 02214, USA.

E-mail: giocomo@gmail.com

Accepted for publication 30 August 2006

DOI 10.1002/hipo.20231

Published online 12 October 2006 in Wiley InterScience (www.interscience. wiley.com). moto et al., 1997). In the hippocampus, group II agonists have been shown to presynaptically reduce synaptic transmission in hippocampal mossy fibers (Scanziani et al., 1997) and at perforant path inputs to dentate gyrus (DG) and to stratum lacunosum moleculare (SLM) of CA1 (Kew et al., 2001) while group III agonists have been shown to presynaptically reduce synaptic transmission in SLM of CA1 (Capogna, 2004), Schaffer collateral inputs in stratum radiatum (SR) (Gereau and Conn, 1995; Vignes et al., 1995), mossy fiber inputs to CA3 pyramidal cells (Manzoni et al., 1995), and perforant path inputs to granule cells (Dietrich et al., 1997).

Behavioral data indicates that activation of group II and III mGluRs reduces anxiety in animals (Linden et al., 2002; Tatarczynska et al., 2002; Bergink et al., 2004), underlies habituation to odors (Best et al., 2005), and has neuroprotective and antiepileptic effects (Klondzinska et al., 2000; Flor et al., 2002; Folbergrova et al., 2005). In vitro slice work in the hippocampus and piriform cortex has demonstrated a lamina selective change in synaptic transmission due to group III and group II mGluR activation (Koerner and Cotman, 1981; Hasselmo and Bower, 1991; Kew et al., 2001). Anatomical localization of mGluR families indicates that group III mGluRs mediate presynaptic inhibition of excitatory transmission at the Schaffer Collaterals in SR and at the perforant path input to SLM, whereas group II mGluRs are not located in SR and only presynaptically inhibit excitatory transmission at the perforant path input to SLM (Shigemoto et al., 1997). Within the synaptic zone, group II mGluRs are localized to preterminal portions of the axon while group III mGluRs are located on the active zone of the terminal (Shigemoto et al., 1997).

Collectively, physiological and anatomical data suggest that group II and group III mGluRs have different functional roles. We investigated the time course of change in synaptic transmission due to the activation of group II and group III mGluRs in hippocampal region CA1. We found a rapid suppression of synaptic transmission due to activation of group II mGluRs in SLM. Activation of group III mGluRs in SR and SLM resulted in a much slower suppression of synaptic transmission. Understanding the time course of group II and group III mGluRs may indicate their functional significance. 


\section{METHODS}

\section{Experimental Methods}

All experiments were performed using brain slices prepared from young (4-8 weeks old), male Sprague-Dawley rats (Charles River Laboratories, Wilmington, MA) that were deeply anesthetized with halothane (Sigma-Aldrich, St. Louis, $\mathrm{MO}$ ) and rapidly decapitated. Techniques were reviewed and approved by the Institutional Animal Care and Use Committee at Boston University. The brain was removed under $4^{\circ} \mathrm{C}$ artificial cerebrospinal fluid (ACSF) oxygenated by bubbling 95\% $\mathrm{O}_{2} / 5 \% \mathrm{CO}_{2}$ through the solution. The concentrations of the ACSF in millimolar were: $\mathrm{NaCl}$ [124.0], $\mathrm{KCl}$ [2.5], $\mathrm{MgSO}_{4}$ [1.3], Dextrose [10.0], $\mathrm{NaHCO}_{3}$ [26.0], $\mathrm{KH}_{2} \mathrm{PO}_{4}$ [1.2], $\mathrm{CaCl}_{2}$ [2.4]. The brain was mounted on its dorsal surface, offset at $10-15^{\circ}$ from horizontal to effectively preserve the Schaffer collaterals. $400-\mu \mathrm{m}$ thick slices were cut in oxygenated $4^{\circ} \mathrm{C}$ ACSF using a Vibroslicer (World Precision Instruments, Sarasota, FL). The slices near the middle range of the septotemporal axis were kept and the hippocampal regions were dissected from other brain tissue.

The slices of the hippocampus were stored in room temperature ACSF for a minimum of $1 \mathrm{~h}$ before they were transferred to a recording chamber (Fine Science Tools, North Vancouver, Canada). For recording, the slice was submerged in a standard slice chamber with continuously flowing ACSF at $35-37^{\circ} \mathrm{C}$ to simulate realistic body temperature. Unipolar stimulating electrodes (World Precision Instruments, Sarasota, FL) were placed in one of two locations: in stratum radiatum (SR) of CA1 to activate the Schaffer collaterals or in stratum lacunosum moleculare (SLM) of CA1 to activate perforant path fibers (Fig. 1a). Recording electrodes were pulled from $1 \mathrm{~mm}$ borosilicate capillary tubes (World Precision Instruments, Sarasota, FL) using a Sutter Instrument model P-87 pipette puller, filled with $2 \mathrm{M}$ $\mathrm{NaCl}$ (3-6 M $\Omega$ resistance) and placed in either SR or SLM, corresponding to the placement of the stimulating electrode.

Input/output curves were constructed in both SLM and SR (Fig. 1b) for single pulse stimulation, which was delivered once every second. In SLM, stimulation was always delivered at $70 \mu \mathrm{A}$ while in SR stimulation was initially tested at $70 \mu \mathrm{A}$ and if the field potential grew in size or showed population spikes (a field potential caused by the summed inward current during the synchronized spiking of a large number of postsynaptic neurons) the stimulation was reduced to as low as $40 \mu \mathrm{A}$. For all experiments except the paired-pulse experiments, single pulse stimulation was delivered at different temporal offsets from the pressure pulse application, ranging from 10 to $500 \mathrm{~ms}$ and continuing at 1-s intervals (using a Neuro Data Instruments PG4000 digital stimulator and SIU90 stimulus isolation unit, Cygnus Technology, DE). For each experimental data point an agonist was applied only once and the effect was allowed to return to baseline. Data were amplified using an AM Systems Model 1800 AC Amplifier, which was connected to a Micro 1401 ADC that provided input to Spike2 software a

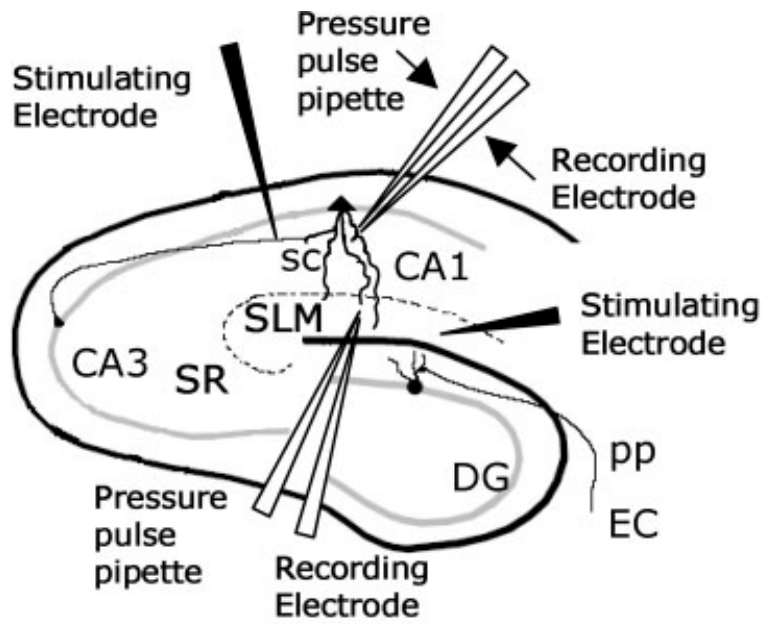

$\mathrm{b}$
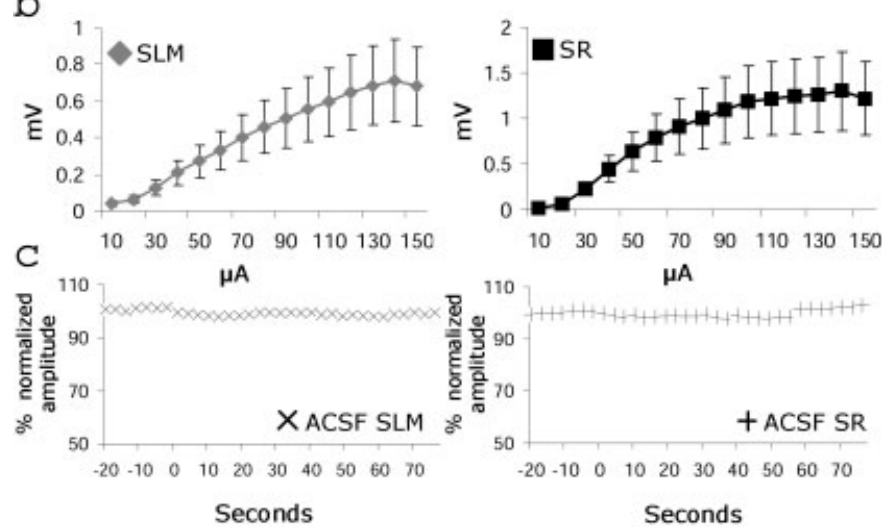

$\begin{array}{llllllll}10 & 30 & 50 & 70 & 90 & 110 & 130 & 150\end{array}$

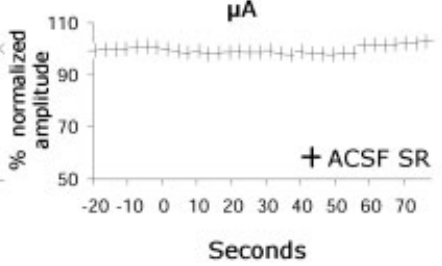

d $(2 R, 4 R)-A P D C$ SLM

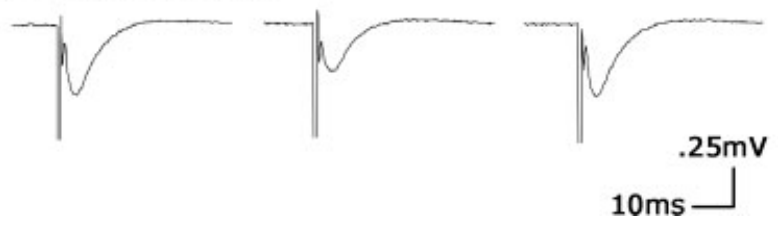

FIGURE 1. Placement of electrodes and example field potentials. (a) Typical placement of stimulating electrode, recording electrode, and pressure pulse pipette in region CA1 of the hippocampus. Stimulating and recording electrodes were placed either in SR to stimulate and record from the Schaffer collaterals or in SLM to stimulate and record from the perforant path fibers. Pressure pulse pipettes were placed as close to the recording electrode as possible. (b) Input/output curves for field potential amplitude in SLM and SR $(n=10)$. (c) Pressure pulse application of ACSF did not significantly change synaptic transmission in SLM or SR. Sampling rate was $1 \mathrm{~Hz}$ and every third measurement point is shown. (d). Example field potentials from SLM in the presence of picrotoxin. Portions of the artifact were removed. Left to right; fEPSP during baseline measurement, $1 \mathrm{~s}$ after pressure pulse application of $50 \mu \mathrm{M}(2 \mathrm{R}, 4 \mathrm{R})-\mathrm{APDC}$, and after return to baseline.

(Cambridge Electronic Designs, Cambridge, UK) on a computer running Windows2000 (Microsoft, Redmond, WA). Pressure pulse ejections were achieved by a multichannel Picospritzer (General Valve), which provided a pulse of pressurized air to eject 
the test solution from a glass micropipette that was distinct from the recording micropipette. A p.s.i. of 10 was used for all experiments and the duration of the ejection $(100 \mathrm{~ms})$ was controlled by the Neurodata digital stimulator. Micropipettes had a tip diameter of approximately $50 \mu \mathrm{m}$. Micropipettes on difference test days released similar amounts of test solution, as determined by observing the ejection under the dissecting microscope.

Before an experiment, a field potential was determined to be stable. Field potentials were considered stable when the potential amplitude did not drift and remained approximately the same size for $5 \mathrm{~min}$. The micropipette filled with test solution was then lowered into position and placed as close to the recording electrode as possible. Although there was a small amount of variation in pulse pipette location this variation was similar between the two layers. At least 20 control potentials were then collected before the ejection of the test solution. After the control potentials were collected, the test solution was ejected at a precise time. The default time delay between the start of the pressure pulse ejection and subsequent stimulus was $500 \mathrm{~ms}$ unless otherwise noted. This default delay was manipulated for most of the test solutions to provide a detailed measurement of the rapid onset of suppression of synaptic transmission. The potential was measured at a rate of once every second until the potential had completely recovered. Potentials that failed to recover to at least $95 \%$ of their baseline amplitude within $10 \mathrm{~min}$ after the pressure pulse ejection were discarded. The average trial length ranged between 100 and $600 \mathrm{~s}$ (100-600 potentials recorded). To ensure that the mechanics of the pressure pulse technique did not cause a change in synaptic transmission, ACSF alone was applied in both SLM and SR using the pressure pulse technique. No notable change in synaptic transmission was observed with the pressure pulse application of ACSF (Fig. 1c). The drugs used in these experiments were as follows: $1 \mathrm{mM}$ L-Glutamic acid (glutamate), $100 \mu \mathrm{M}$ DL-2-Amino-4-phosphonobutyric acid (DL-AP4), $50 \mu \mathrm{M}$ (2R,4R)-Aminopyrrolidine-2,4-dicarboxylate ((2R,4R)-APDC), $100 \mu \mathrm{M}$ (RS)- $\alpha$-Methylserine-O-phosphate (MSOP) and $50 \mu \mathrm{M}$ picrotoxin. The concentration of DL-AP4 was chosen based on full dose response curves constructed in this laboratory for DLAP4 in SLM and SR of CA1 (Fig. 4d). (2R,4R)-APDC was used as it is a highly potent, commercially available, group II mGluR agonist (Jane and Doherty, 2000). A $50 \mu \mathrm{M}$ concentration was used of the selective group II mGluR agonist $(2 \mathrm{R}, 4 \mathrm{R})$ APDC in the pressure pulse pipette, as (2R,4R)-APDC loses its selective agonist effects at concentrations higher than $100 \mu \mathrm{M}$ (Shoepp et al., 1999). $50 \mu \mathrm{M}$ picrotoxin was added to the perfusate to block inhibitory $\mathrm{Cl}^{-}$currents due to $\mathrm{GABA}_{\mathrm{A}}$ receptor activation (Mott and Lewis, 1991; Solis and Nicoll, 1992). Glutamate and picrotoxin were obtained from Sigma; all other drugs were obtained from Tocris-Cookson.

For experiments involving MSOP, $100 \mu \mathrm{M}$ MSOP was added to the solution of ACSF and applied using bath perfusion. For these experiments, glutamate was ejected from the pressure pulse pipette in the presence of normal ACSF and the effect of glutamate was measured. After a 20-min wash period, the ACSF with $100 \mu \mathrm{M}$ MSOP added was used as the perfus- ate. After allowing $15 \mathrm{~min}$ for the new perfusate to saturate the slice chamber, another pressure pulse ejection of glutamate was applied and the effect of the glutamate in the presence of the MSOP was measured to establish whether the effect changed as a result of the presence of MSOP. A $500 \mathrm{~ms}$ delay was used for MSOP experiments in SLM while a $100 \mathrm{~ms}$ delay was used for the MSOP experiments in SR.

For paired pulse experiments, paired pulse stimulation was delivered with a $100 \mu$ s interstimulus interval, with pulse pairs applied every $5 \mathrm{~s}$. Paired pulse facilitation (PPF) was calculated by dividing the height of the second pulse by the height of the first pulse and normalizing it to the baseline PPF to provide a within subjects control variance. For paired pulse experiments with (2R,4R)-APDC, paired pulse stimulation was delivered every $5 \mathrm{~s}$.

In separate experiments, paired pulse facilitation dose response curves were constructed for DL-AP4 in both SLM and SR. For the dose response curve experiments, the potential was allowed to stabilize, and recording began with a $10 \mathrm{~min}$ baseline, followed by a 10 min perfusion of $1,4,10,40,100$, or $400 \mu \mathrm{M}$ DL-AP 4 (Sigma-Aldrich, St. Louis, MO), and ended with a 30-40 min washout period to ensure fEPSPs returned to more than $95 \%$ of baseline. For data analysis, the baseline amplitude was calculated by averaging the amplitude of $10 \mathrm{fEPSPs}$ before perfusion.

\section{Measurement of Synaptic Potentials and Quantification of Modulatory Time Course}

Spike 2 was used to collect synaptic field potentials and measure the amplitude of each. The amplitude of the field potentials was taken by measuring the voltage just before a stimulating pulse and subtracting the maximum trough point of the synaptic potential that occurred within a fixed window of $2.7-8 \mathrm{~ms}$ after the stimulating pulse. Figure 1d presents examples of individual field potentials in SLM. Initial time course plots were calculated as a percentage of baseline (average of 10 potentials before pressure pulse application). In some cases, they were normalized by setting zero as the maximum suppression value.

To measure the onset and decay of modulatory effects on recorded synaptic potentials, the curve-fitting tool in MATLAB was used to fit a dual exponential curve to the data. Dual exponential equations have been used both to model the time course of synaptic potentials (Otis et al., 1993; Wilson and Bower, 1992) and the time course of modulatory influences on synaptic potentials (Hasselmo and Fehlau, 2001). Here they were used to fit averaged time course data on suppression for each experiment group and provided values for the onset and decay time constants of suppression in the following dual-exponential equation:

$$
W(t)=B-z\left(\frac{\tau_{2} \tau_{1}}{\tau_{2}-\tau_{1}}\right)\left(e^{-t / \tau_{2}}-e^{-t / \tau_{1}}\right) .
$$

$W(t)$ is the amplitude of the synaptic potential as a function of time, $t$, in seconds. $B$ represents the baseline amplitude of synaptic potentials. The constant $B$ was determined before using the equation by using the baseline amplitude of the synaptic potentials. All other constants, including the square of the coefficient 
of variation $R^{2}$, were derived using the curve-fitting tool in MATLAB 7.0 on Windows XP. $z$ is a constant used as a scaling factor proportional to the magnitude of suppression. $\tau_{1}$ represents the fitted onset time course (in seconds) of suppression of synaptic transmission. $\tau_{2}$ represents the fitted decay time course (in seconds) for the speed at which the effect returns to baseline.

\section{RESULTS}

Time Course of Modulation of Synaptic Transmission by Glutamate

Initial experiments used the pressure pulse protocol to apply $1 \mathrm{mM}$ glutamate, in the presence of $50 \mu \mathrm{M}$ picrotoxin, $500 \mathrm{~ms}$ (ms) prior to an evoked field potential in both SR and SLM in CA1, followed by stimulation at 1-s intervals. Pressure pulse application caused a temporary suppression of the amplitude of recorded field potentials in both SLM and SR (Fig. 2a).

In SLM, pressure pulse application of $1 \mathrm{mM}$ glutamate resulted in a very rapid suppression of synaptic transmission $\left(\tau_{1}=1.1 \pm\right.$ $\left.0.04 \mathrm{~s}, n=5, R^{2}=0.99\right)$ followed by a longer return to baseline amplitude $\left(\tau_{2}=95.9 \pm 1.7 \mathrm{~s}, n=5, R^{2}=0.99\right)$. Conversely, pressure pulse application of $1 \mathrm{mM}$ glutamate with a $500 \mathrm{~ms}$ delay in SR (Fig. 2a) resulted in a much slower suppression of the amplitude of field potentials $\left(\tau_{1}=4.4 \pm 0.8 \mathrm{~s}, n=5, R^{2}=0.85\right)$ followed by a longer return to baseline amplitude $\left(\tau_{2}=165 \pm\right.$ $10.3 \mathrm{~s}, n=5, R^{2}=0.85$ ). The time course data points were also plotted after being normalized to the maximum suppression value, further illustrating the markedly faster onset of suppression of synaptic transmission in SLM when compared with that in SR (Fig. 2b). Additional time delays between pressure pulse application and the first subsequent stimulus were used to specifically examine the onset of suppression at a higher temporal resolution (Fig. 2c). Recordings taken during the higher temporal resolution involved a shift in the phase of the pressure pulse. For each experimental data point, the pressure pulse application occurred only once and the effect was allowed to completely recover before another experimental data point was taken. The higher temporal resolution confirmed the very rapid suppression of synaptic transmission due to the application of $1 \mathrm{mM}$ glutamate in SLM and also verified the slower suppression of synaptic transmission in SR due to the application of $1 \mathrm{mM}$ glutamate (Fig. 2c).

Although a lamina specific difference in the time course of the onset of suppression was observed with the pressure pulse ejection of $1 \mathrm{mM}$ glutamate, glutamate does not differentially affect group II and group III mGluRs but instead has complex effects at multiple glutamatergic receptor subtypes. For this reason, specific antagonists and agonists were used to examine the time course at different groups of mGluRs more specifically.

\section{Time Course of Modulation of}

\section{Synaptic Transmission by mGluRII} Agonist (2R,4R)-APDC

Metabotropic glutamate receptor group selective agonists were used to more specifically identify the role of each presyn-
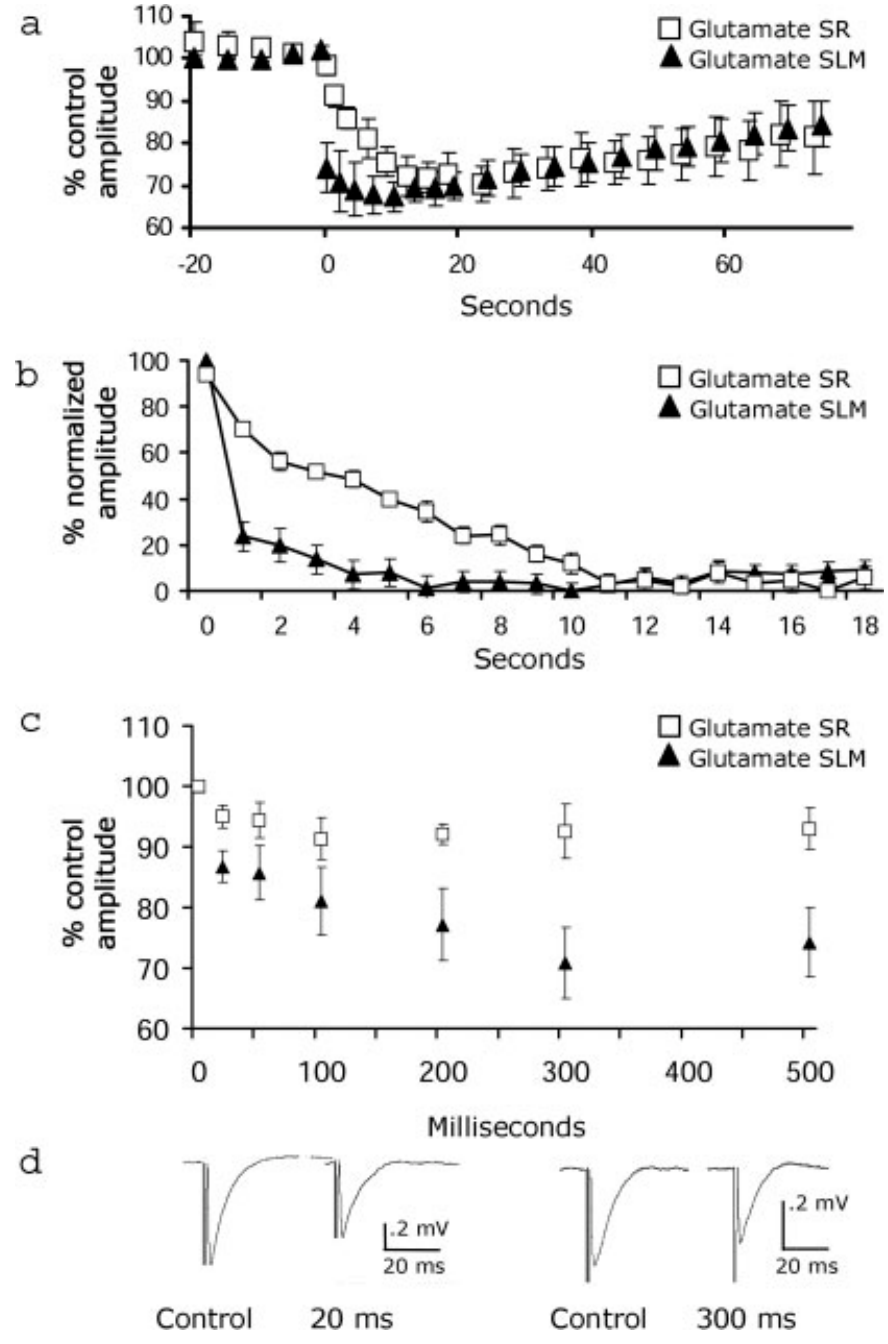

FIGURE 2. Time courses of modulation by $1 \mathrm{mM}$ glutamate in the presence of picrotoxin in SR and SLM. Evoked fEPSPs in all figures shown returned back to baseline; only the first part of the data is shown to highlight the difference in the onset time course. Points are shown every other plot from 0 to $20 s$ and every fourth plot after $20 \mathrm{~s}$. (a) $1 \mathrm{mM}$ glutamate resulted in a much faster onset of suppression of synaptic transmission in SLM (filled triangles, $n=5$ ) when compared with SR (empty squares, $n=5$ ). (b) Suppression of synaptic transmission in SR and SLM after amplitude measurement was normalized to the maximum suppression value reached after the application of glutamate. The amount of suppression in SLM $(n=5)$ was larger than in SR $(n=5)$. However, after the onset points are normalized to the maximum suppression value the onset of suppression in SLM is still clearly faster than the onset of suppression in SR. (c) Suppression values obtained at 6 different offset delays $(10,50,100,200,300,500)$ before the first stimulation after the pressure pulse application of glutamate in SR and SLM. Each point represents 5-7 measurements from different experiments. The difference in the onset of suppression is observed even in the first $500 \mathrm{~ms}$ after glutamate application. (d) Examples of field potentials from experiments in Figure 2c. Left: Control field potential and field potential $20 \mathrm{~ms}$ after application of $1 \mathrm{mM}$ glutamate in SLM. Right: Control field potential and field potential $300 \mathrm{~ms}$ after application of $1 \mathrm{mM}$ glutamate in SLM. 

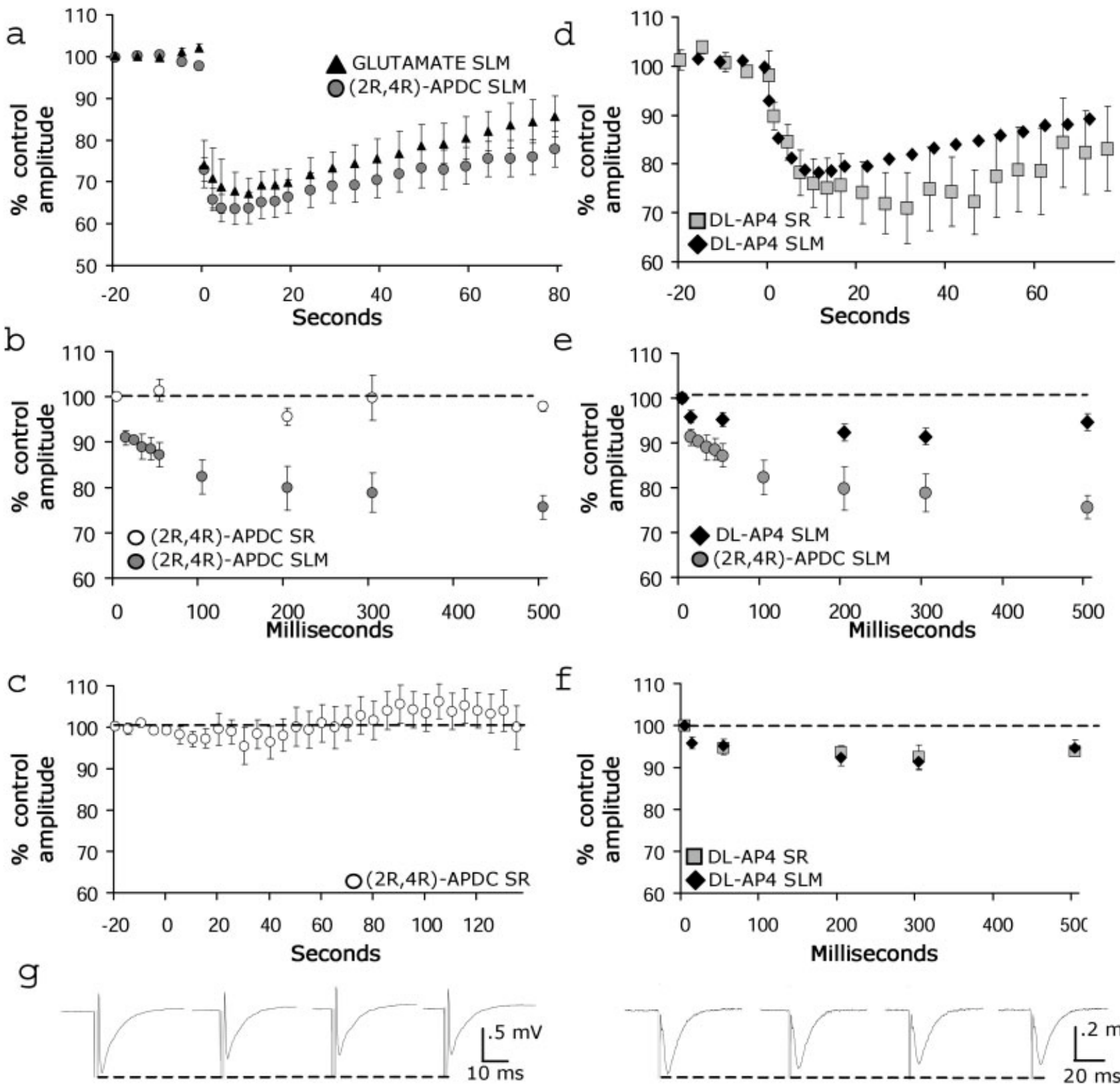

$(2 \mathrm{R}, 4 \mathrm{R})-\mathrm{APDC}$

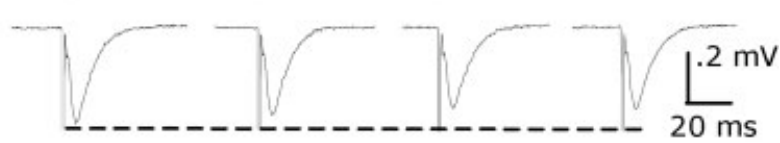

DL-AP4

FIGURE 3. Time course of modulation by (2R,4R)-APDC or DL-AP4 in the presence of picrotoxin in SLM and SR. Evoked fEPSPs in all figures shown returned back to baseline; only the first part of the data is shown to highlight the difference in the onset time course. Points are shown every other plot from 0 to $20 \mathrm{~s}$ and every fourth plot after $20 \mathrm{~s}$. (a) Pressure pulse application of $50 \mu M(2 R, 4 R)-A P D C$ in SLM $(n=11)$ resulted in a fast onset of suppression of synaptic transmission followed by a slow, complete return to baseline. Pressure pulse application of $1 \mathrm{mM}$ glutamate and $(2 R, 4 R)-A P D C$ in SLM resulted in a similar onset of suppression of synaptic transmission. (b) Suppression at various delays within the first $500 \mu s$ after pressure pulse application of (2R,4R)-APDC in SLM and SR. Each data point represents 5-14 measurements from different experiments. In SLM (2R,4R)-APDC resulted in a rapid suppression of synaptic transmission followed by a complete return to baseline while ( $2 R, 4 R)$-APDC application in SR had no effect on synaptic transmission. (c) Pressure pulse application of $50 \mu M(2 R, 4 R)-A P D C$ in SR $(n=11)$ had no effect

on synaptic transmission. (d) Comparison of the application of DLAP4 in SLM $(n=9)$ and SR $(n=7)$. DL-AP4 caused slightly more suppression in SR when compared with that in SLM but onset time course constants for both layers were similar (see results). (e) Comparison of suppression at various delays within the first $500 \mathrm{~ms}$ after pressure pulse application of $(2 R, 4 R)-A P D C$ and DL-AP4 in SLM. Each data point represents 5-9 measurements from different experiments. Application of either drug caused suppression of synaptic transmission, but the onset of the suppression was clearly much faster for $(2 R, 4 R)-A P D C$ than DL-AP4 in SLM. (f) The first $500 \mathrm{~ms}$ after pressure pulse application of DL-AP4 in SLM and SR. Each data point represents 6-10 measurements from different experiments. The onset of suppression for the first $500 \mathrm{~ms}$ after DL-AP4 was very slow and strikingly similar in both layers. (g) Examples of field potentials from Figure $3 \mathrm{e}$ in SLM after application of (2R,4R)-APDC (left) or DL-AP4 (right). Field potentials are shown (from left to right) during control conditions, 1, 5, and $10 \mathrm{~s}$, after application of $(2 R, 4 R)-A P D C$ or DL-AP4. 
aptic receptor group in the suppression of synaptic transmission and their respective time courses.

Pressure pulse ejection of $50 \mu \mathrm{M}(2 \mathrm{R}, 4 \mathrm{R})$-APDC with the $500 \mathrm{~ms}$ delay in SLM resulted in a very rapid decrease in the amplitude of the synaptic potential followed by a slower return back to baseline (Fig. 3a). The onset of suppression due to application of $(2 \mathrm{R}, 4 \mathrm{R})-\mathrm{APDC}$, as seen in Figure $3 \mathrm{a}$, showed the same rapid suppression of synaptic transmission $\left(\tau_{1}=1 \pm\right.$ $\left.0.1 \mathrm{~s}, n=11, R^{2}=0.99\right)$ as the onset of suppression due to the application of $1 \mathrm{mM}$ glutamate in SLM, as seen in Figure $2 \mathrm{a}\left(\tau_{1}=1.1 \pm 0.1 \mathrm{~s}, n=5\right)$. The rapid onset of suppression in SLM was followed by a slower return to baseline $\left(\tau_{2}=134 \pm\right.$ $\left.1.9 \mathrm{~s}, n=11, R^{2}=0.99\right)$. At a higher temporal resolution, the onset time course of $(2 \mathrm{R}, 4 \mathrm{R})$-APDC was characterized by a very rapid suppression of synaptic transmission over the first $500 \mathrm{~ms}$ (Fig. 3b), followed by a slower increase in suppression that continued to a maximum suppression value five seconds after the pulse of (2R,4R)-APDC (Fig. 3a), before starting a return to the original baseline measurement of field potential amplitude. The higher temporal resolution revealed that the onset of suppression of synaptic transmission in SLM after the application of (2R,4R)-APDC (Fig. 3b) was almost identical to that observed after the application of $1 \mathrm{mM}$ glutamate (Fig. 2c). Although the onset of suppression due to (2R,4R)APDC in SLM was similar to $1 \mathrm{mM}$ glutamate in SLM, the decay time for $(2 \mathrm{R}, 4 \mathrm{R})$-APDC was slightly slower than the decay time for $1 \mathrm{mM}$ glutamate, most likely due to the absence of reuptake mechanisms for a nonendogenous substance.

Pressure pulse ejection of $50 \mu \mathrm{M}(2 \mathrm{R}, 4 \mathrm{R})$-APDC resulted in no change in synaptic transmission in SR (Fig. 3c), supporting anatomical data indicating that group II mGluRs are not localized in SR of CA1 (Shigemoto et al., 1997). Figure 3b compares the first $500 \mathrm{~ms}$ after the pressure pulse ejection of (2R,4R)-APDC in SLM and SR. The fast onset of suppression in SLM due to application of $(2 \mathrm{R}, 4 \mathrm{R})$-APDC suggests that the activation of group II mGluRs is the mechanism underlying the fast onset of suppression observed in SLM due to the application of glutamate. Group II mGluRs are not localized in SR (Shigemoto et al., 1997) however, suggesting a different mGluR family contributes to the slower onset of suppression observed in SR after application of glutamate.

\section{Time Course of Modulation of Synaptic Transmission by mGluRIII agonist DL-AP4}

To determine the role of group III mGluRs in the time course of suppression of synaptic transmission, pressure pulse ejections with a selective group III agonist, DL-AP4, were run in both SLM and SR. Unlike group II mGluRs, group III mGluRs are localized in both SLM and SR of CA1 in the hippocampus (Shigemoto et al., 1997). The concentration of 100 $\mu \mathrm{M}$ DL-AP4 was chosen based on dose response data collected from this laboratory (unpublished observations). Bath application of $100 \mu \mathrm{M}$ DL-AP4 in SR resulted in a $22.44 \%$ (standard error $(\mathrm{SE})=5.12, n=4)$ suppression of synaptic transmission and a $49.76 \%(\mathrm{SE}=6.30, n=4)$ suppression of synaptic transmission in SLM (Fig. 4d). DL-AP4 at $400 \mu \mathrm{M}$ failed to cause more suppression in either layer.

In SLM, pressure pulse ejections of $100 \mu \mathrm{M}$ DL-AP4 with the 500 ms delay (Fig. 3d) resulted in a slower decrease in field potential amplitude $\left(\tau_{1}=3.8, \pm 0.2 \mathrm{~s}, n=9, R^{2}=0.99\right)$ relative to $(2 R, 4 R)-A P D C$, followed by a slow return to the baseline amplitude $\left(\tau_{2}=79.04 \pm 1.8 \mathrm{~s}, n=9, R^{2}=0.99\right)$. The onset time for DL-AP4 in SLM was very similar to the onset time for $1 \mathrm{mM}$ glutamate in $\mathrm{SR}$, as seen in Figure $2 \mathrm{a}\left(\tau_{1}=\right.$ $4.4 \pm 0.8 \mathrm{~s})$ but slower than the onset time constant for $(2 \mathrm{R}, 4 \mathrm{R})-\mathrm{APDC}$ in SLM, as seen in Figure $3 \mathrm{a}\left(\tau_{1}=1 \pm 0.1 \mathrm{~s}\right)$. At the higher temporal resolution, the onset of suppression seen after the application of DL-AP4 was slower than the onset of suppression observed in the same layer with the application of (2R,4R)-APDC (Fig. 3e).

Pressure pulse ejections of $100 \mu \mathrm{M}$ DL-AP4 in SR also resulted in a slower decrease in field potential amplitude $\left(\tau_{1}=\right.$ $\left.7.8 \pm 1 \mathrm{~s}, n=7, R^{2}=0.91\right)$, followed by a slow return to the baseline amplitude $\left(\tau_{2}=97.1 \pm 6.6 \mathrm{~s}, n=7, R^{2}=0.91\right)$. Figure $3 \mathrm{~d}$ compares the effect of DL-AP4 in SR with the effect of DL-AP4 in SLM, showing a similar slow time course. At the higher temporal resolution, application of DL-AP4 in SR revealed an onset of suppression very similar to the application of DL-AP4 in SLM at the higher temporal resolution (Fig. 3f).

\section{Pressure Pulse Application of Glutamate in the Presence of Group III Antagonist MSOP}

To confirm the contribution of group III mGluRs to the slow onset of suppression in SR and the contribution of group II mGluRs to the fast onset of suppression in SLM, glutamate was applied in the absence and presence of the selective group III mGluR antagonist MSOP. In SLM, the fast suppression of synaptic transmission was observed both in the absence $\left(\tau_{1}=1.6 \pm\right.$ $\left.2.2 \mathrm{~s}, n=4, R^{2}=0.94\right)$ and presence of $100 \mu \mathrm{M}$ MSOP $\left(\tau_{1}=0.3 \pm 0.2 \mathrm{~s}, n=4, R^{2}=0.97\right.$ ), (Fig. 4a) supporting the conclusion that group II mGluRs underlie the fast onset of suppression observed in SLM with pressure pulse application of glutamate and $(2 \mathrm{R}, 4 \mathrm{R})$-APDC. The similarity between the onset time constant in SLM for $(2 \mathrm{R}, 4 \mathrm{R})$-APDC and glutamate in the presence of MSOP indicates that the fast suppression of synaptic transmission is not due to chemical properties of (2R,4R)-APDC. The slightly slower onset of suppression by glutamate in the absence of MSOP when compared with the previously measured onset of suppression by glutamate in SLM is most likely due to a difference in the size of the samples.

In $S R$, pressure pulse application of glutamate in the absence of MSOP resulted in a slow onset of suppression of synaptic transmission $\left(\tau_{1}=6.9 \pm 0.2 \mathrm{~s}, n=3\right)$ followed by a slow, complete return to baseline ( $\left.\tau_{2}=234.6 \pm 14 \mathrm{~s}, n=3\right)$. In the presence of MSOP, pressure pulse application of glutamate in SR resulted in a very small depression of synaptic transmission, indicating that group III mGluRs produce most of the slow onset of suppression observed with glutamate application in SR (Fig. 4b). 
a

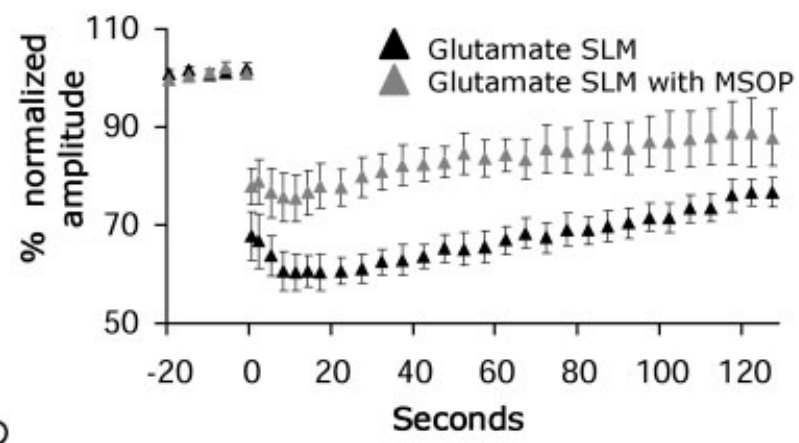

$\mathrm{b}$
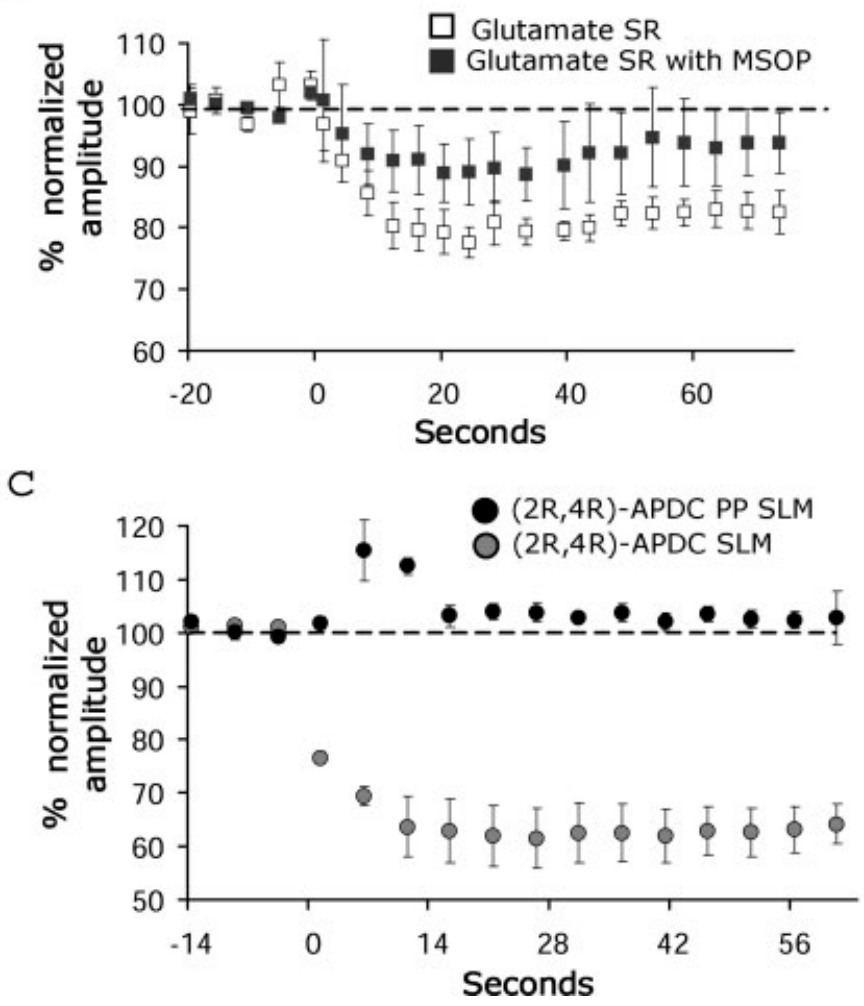

FIGURE 4. Effects of glutamate in the absence and presence of the group III antagonist MSOP and paired pulse facilitation due to application of $(2 R, 4 R)$-APDC or DL-AP4. Evoked fEPSPs in all figures shown returned back to baseline; only the first part of the data is shown to highlight the difference in the onset time course. Points are shown every other plot from 0 to $20 s$ and every fourth plot after $20 \mathrm{~s}$. (a) Pressure pulse application of glutamate in SLM $(n=4)$ in the presence of MSOP resulted in similar substantial suppression with a faster onset of suppression than without MSOP, but a lower maximum amplitude. (b) Pressure pulse application of glutamate in SR $(n=3)$ in the presence and absence

\section{Paired Pulse Stimulation}

To confirm that the modulation of synaptic transmission by (2R,4R)-APDC in SLM and DL-AP4 in SLM and SR was due to activation of presynaptic receptors, paired pulse experiments were performed. Pressure pulse application of (2R,4R)-APDC in SLM resulted in an immediate, large increase in paired pulse facilitation that lasted for approximately $15 \mathrm{~s}$, then declined to d
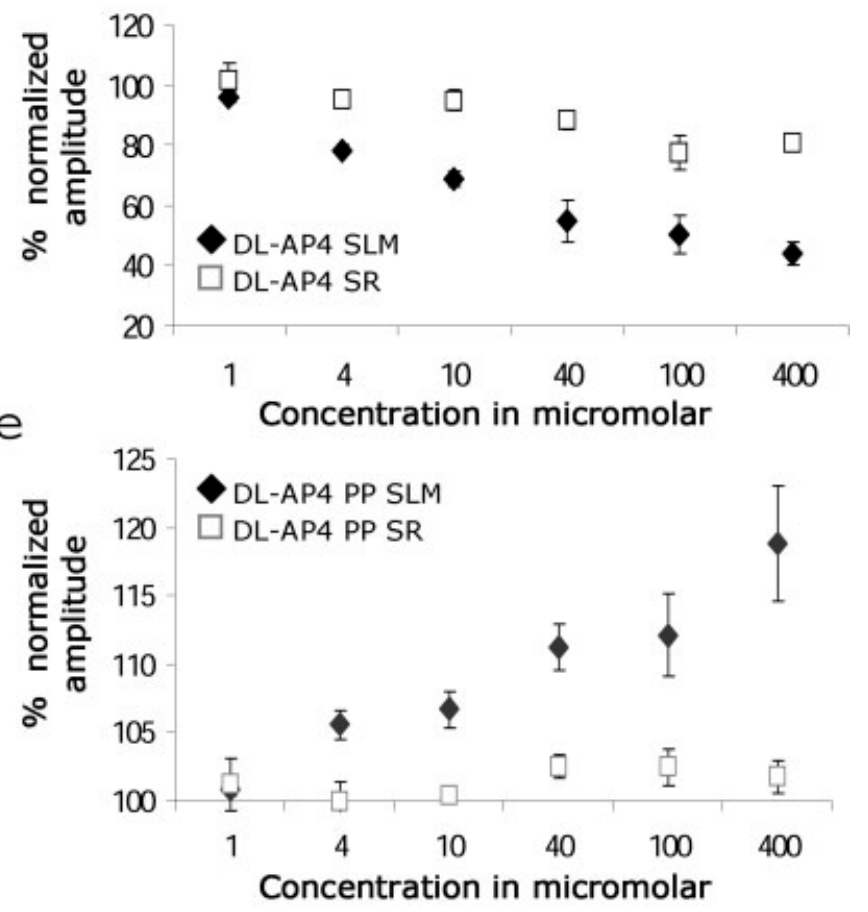

of MSOP. In the presence of MSOP, the glutamate application had little effect on synaptic transmission. (c) The time course of magnitude of paired pulse facilitation compared with the time course of suppression of potentials observed after the pressure pulse application of $(2 R, 4 R)-A P D C$ in SLM $(n=5)$. The suppression due to $(2 \mathrm{R}, 4 \mathrm{R})-\mathrm{APDC}$ observed with the paired pulse recordings was slightly more prolonged. (d) Dose response curve for suppression of potentials by DL-AP4 in SLM and SR. Each data point represents 4-7 measurements from different experiments. (e) Dose response curve of paired pulse facilitation for DL-AP4 in SLM and SR. Each data point represents 4-7 measurements from different experiments. a lower but still enhanced level of paired pulse facilitation that lasted until synaptic transmission returned to baseline (Fig. 4c). For DL-AP4, dose response curves were constructed for suppression of synaptic transmission (Fig. 4d) and paired-pulse facilitation in both SLM and SR of CA1 (Fig. 4e). DL-AP4 caused a large dose dependent increase in paired pulse facilitation in SLM and a smaller but significant increase in SR. Com- 
bined, these results support the presynaptic action of $(2 \mathrm{R}, 4 \mathrm{R})$ APDC and DL-AP4 in SLM. In SR, however, DL-AP4 only caused a small increase in paired pulse facilitation.

\section{The Effect of GABA Activation on Time Course}

Recent research has demonstrated that group II and group III mGluRs can modulate the activity of interneurons in CA1 of the hippocampus (Mitchell and Silver, 2000; Kogo et al., 2004; Price et al., 2005). Since the initial experiments all used a bath application of $50 \mu \mathrm{M}$ picrotoxin to block inhibitory $\mathrm{Cl}^{-}$currents due to the activation of GABAergic interneurons, picrotoxin was removed from the bath to examine the potential role of $\mathrm{GABA}_{\mathrm{A}}$ receptors in determining the time course of the onset of suppression.

The application of $1 \mathrm{mM}$ glutamate in the absence of picrotoxin revealed a biphasic suppression of synaptic potentials (Fig. 5a and 5b). The biphasic effect contributed to a very fast onset time course of suppression of synaptic transmission in SLM $\left(\tau_{1}=0.2 \pm 0.5 \mathrm{~s}, n=11, R^{2}=0.92\right)$ followed by a slightly slower return to baseline $\left(\tau_{2}=122.8 \pm 5.2 \mathrm{~s}, n=11\right.$, $\left.R^{2}=0.92\right)$ when compared with the application of glutamate in the presence of picrotoxin. The higher temporal resolution revealed that the complete biphasic effect on field potential amplitude could be observed in its entirety only in the detailed time course (shown in Fig. 5b).

Pressure pulse application of $1 \mathrm{mM}$ glutamate with a $500 \mu \mathrm{s}$ delay in SR, in the absence of picrotoxin, still resulted in a much slower suppression of the amplitude of the field potential $\left(\tau_{1}=10.9 \pm 0.7 \mathrm{~s}, n=12, R^{2}=0.96\right)$ when compared with that in SLM (Fig. 5a), followed by a slow, complete return to baseline $\left(\tau_{2}=204.8 \pm 5.2 \mathrm{~s}, n=12, R^{2}=0.96\right)$. In SR, the onset of suppression in the absence of picrotoxin, as seen in Figure $5 \mathrm{a}$, was even slower than the onset of suppression in the presence of picrotoxin, as seen in Figure $2 \mathrm{a}\left(\tau_{1}=4.4 \pm 0.8 \mathrm{~s}\right)$. Several different delays were chosen to examine the onset time course of suppression at a higher temporal resolution and compare the onset time course in SR to the onset time course of suppression in SLM (Fig. 5b).

In SLM, pressure pulse ejection of $50 \mu \mathrm{M}(2 \mathrm{R}, 4 \mathrm{R})$-APDC with the $500 \mu$ s delay was also investigated in the absence of picrotoxin. Application of $(2 \mathrm{R}, 4 \mathrm{R})$-APDC in SLM resulted in a very rapid decrease in the amplitude of the synaptic potentials $\left(\tau_{1}=0.2 \pm 0.5 \mathrm{~s}, n=8, R^{2}=0.93\right)$ followed by a slower rise back to baseline $\left(\tau_{2}=182.1 \pm 6.8 \mathrm{~s}, n=8, R^{2}=0.93\right)$, similar to that observed in the presence of picrotoxin. The onset time constant for $(2 \mathrm{R}, 4 \mathrm{R})$-APDC in the absence of picrotoxin was slightly faster than the fast onset observed after the application of $(2 \mathrm{R}, 4 \mathrm{R})$-APDC in the presence of picrotoxin $\left(\tau_{1}=1 \pm\right.$ $0.1, n=7)$. Similar to the higher temporal resolution time course of the application of $1 \mathrm{mM}$ glutamate in SLM without picrotoxin, application of (2R,4R)-APDC without picrotoxin also resulted in a pronounced biphasic effect (Fig. 5c). Figure $5 \mathrm{~d}$ shows the onset of suppression of synaptic transmission in SLM, normalized to the maximum suppression value, due to application of (2R,4R)-APDC and $1 \mathrm{mM}$ glutamate showing a biphasic effect in the absence but not in the presence of picrotoxin. The effect of $(2 \mathrm{R}, 4 \mathrm{R})-\mathrm{APDC}$ in the absence of picrotoxin was not investigated in SR because of the absence of any effect in the previous experiments.

The effect of DL-AP4 in the absence of picrotoxin was also investigated. In SLM pressure pulse ejections of $100 \mu \mathrm{M}$ DLAP4 with the $500 \mathrm{~ms}$ delay resulted in a slower decrease in field potential amplitude $\left(\tau_{1}=4.1 \pm 0.3 \mathrm{~s}, n=8, R^{2}=\right.$ $0.98)$ followed by a slow return to the baseline amplitude $\left(\tau_{2}=85.1 \pm 2.4 \mathrm{~s}, n=8, R^{2}=0.98\right)$. The onset time constant for the pressure pulse application of DL-AP4 in the absence of picrotoxin in SLM $\left(\tau_{1}=4.1 \pm 0.3 \mathrm{~s}, n=8\right)$ was almost identical to the onset time constant due to the application of DLAP4 in the presence of picrotoxin in SLM, as seen in Figure 5e $\left(\tau_{1}=3.8 \pm 0.2 \mathrm{~s}\right)$, and the onset time constant due to the application of glutamate in the presence of picrotoxin in SR $\left(\tau_{1}=4.4 \pm 0.8 \mathrm{~s}\right.$; Fig. 2a). Figure 5 e illustrates the similarity of DL-AP4's effect on synaptic transmission in SLM in the presence and absence of picrotoxin. In SR, pressure pulse ejection of $100 \mu \mathrm{M}$ DL-AP4 with the 500 ms delay resulted in a slower decrease in field potential amplitude $\left(\tau_{1}=12.3 \pm 0.9 \mathrm{~s}\right.$, $\left.n=9, R^{2}=0.97\right)$ and a slow, complete return to baseline amplitude ( $\left.\tau_{2}=102 \pm 3.8 \mathrm{~s}, n=9, R^{2}=0.97\right)$. The onset time constant for DL-AP4 in SR (Fig. 5f) was slower than the onset time constant for DL-AP4 in SLM $\left(\tau_{1}=4.1 \pm 0.3 \mathrm{~s}\right.$; Fig. 5e) and DL-AP4 in SR $\left(\tau_{1}=7.8 \pm 1 \mathrm{~s}\right.$; Fig. $\left.3 \mathrm{~d}\right)$ with picrotoxin present. The slower onset time constant for DL-AP4 in SR could be due to the slow decline into a steady suppression value when compared with a somewhat faster decline into and much faster rise out of a maximum suppression value for DLAP4 in the presence of picrotoxin (Fig. 5f).

\section{DISCUSSION}

Our results indicate that group II mGluRs cause a much faster onset of presynaptic inhibition than group III mGluRs. Pressure pulse application of $1 \mathrm{mM}$ glutamate resulted in a faster onset of suppression of synaptic transmission in SLM compared with that in SR. Application of the group II mGluR agonist (2R,4R)-APDC in SLM resulted in a similar fast onset of suppression (Fig. 3a) suggesting that the fast onset of suppression in SLM, due to the application of $1 \mathrm{mM}$ glutamate, is caused by the activation of group II mGluRs. Pressure pulse application of the group III agonist DL-AP4 caused a slower onset of suppression (Fig. 3e) when compared with (2R,4R)APDC in SLM, which was observed even after normalizing the data to the maximum suppression value (Fig. 6a). In SR, the onset of suppression for DL-AP4 was very similar to the onset of suppression for glutamate in SR and DL-AP4 in SLM (Fig. 6b). Combined, the time course of DL-AP4 modulation of synaptic potentials suggests that the slower suppression of synaptic transmission observed in SR after the application of $1 \mathrm{mM}$ glutamate is due to activation of group III mGluRs.

Pressure pulse application of DL-AP4 caused a slightly faster onset of suppression in SLM than in SR (Fig. 6b), suggesting 


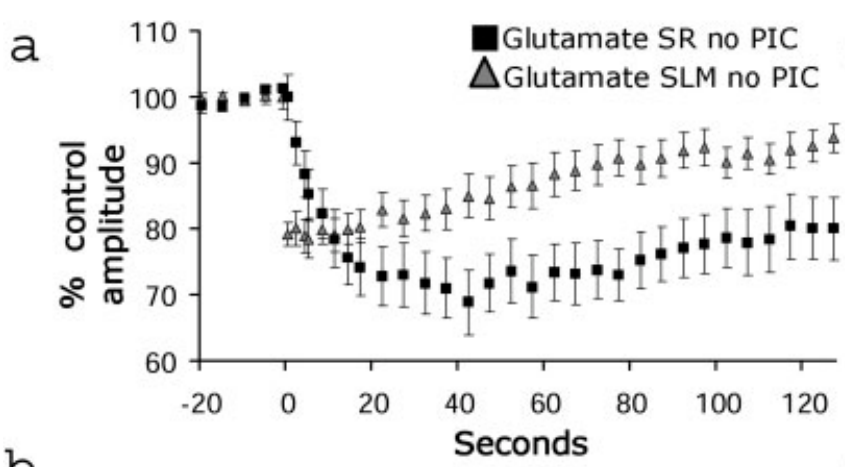

$\mathrm{b}$
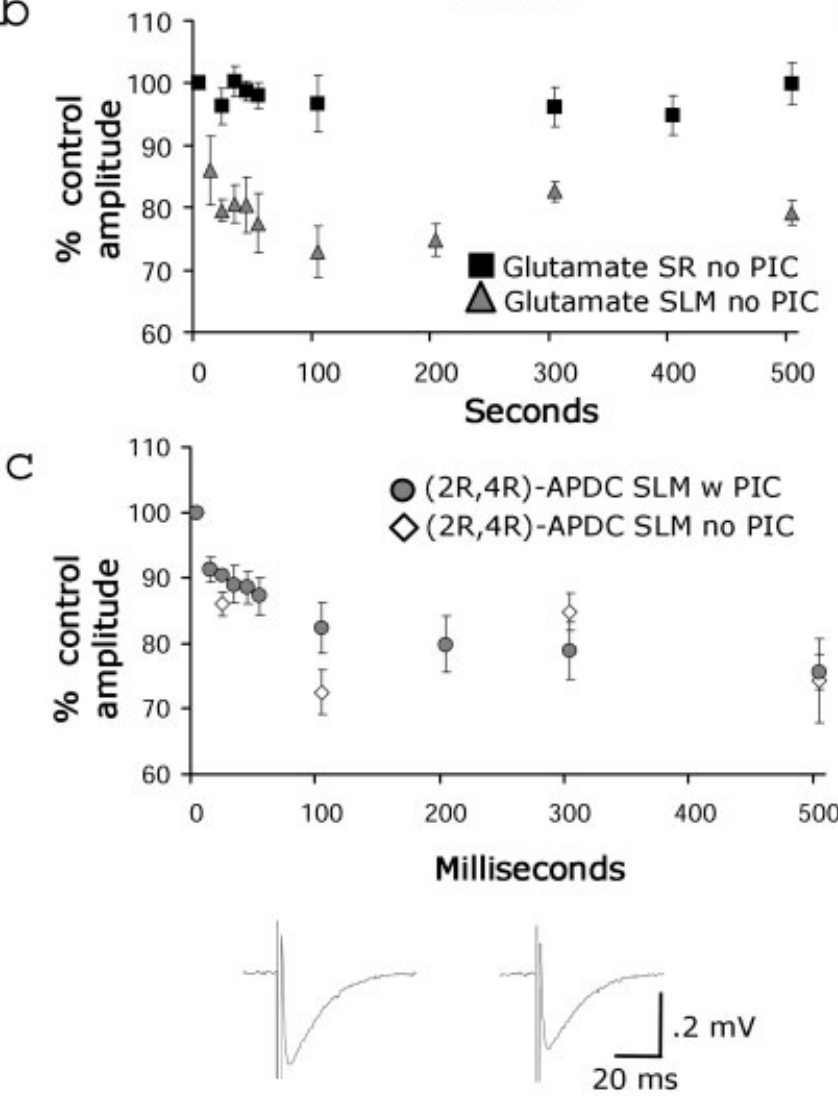

Picrotoxin

FIGURE 5. Effects of glutamate, (2R,4R)-APDC, and DL-AP4 in SLM or SR in the absence of picrotoxin. Evoked fEPSPs in all figures shown returned back to baseline; only the first part of the data is shown to highlight the difference in the onset time course. Points are shown every other plot from 0 to $20 s$ and every fourth plot after $20 \mathrm{~s}$. (a) Pressure pulse application of $1 \mathrm{mM}$ glutamate in the absence of picrotoxin resulted in a faster onset of suppression in SLM $(n=11)$ when compared with that in SR $(n=12)$ and more suppression in SR when compared that in SLM. (b) Suppression at different delays during the first $500 \mathrm{~ms}$ after pressure pulse application of glutamate in SLM and SR. Glutamate caused a fast onset of suppression of synaptic transmission in SLM (each data point represents 5-14 measurements from different experiments) while glutamate caused a slow onset of suppression in SR (each data point represents 5-8 measurements from different experiments). (c) In SLM, (2R,4R)-APDC pressure pulse application in the presence and absence (each data point represents 4-5 measurements from different experiments) of picrotoxin. (d) Effects of glutamate with picrotoxin, glutamate without picrotoxin, $(2 \mathrm{R}, 4 \mathrm{R})-\mathrm{APDC}$ with picrotoxin, and $(2 \mathrm{R}, 4 \mathrm{R})$-APDC without pic-
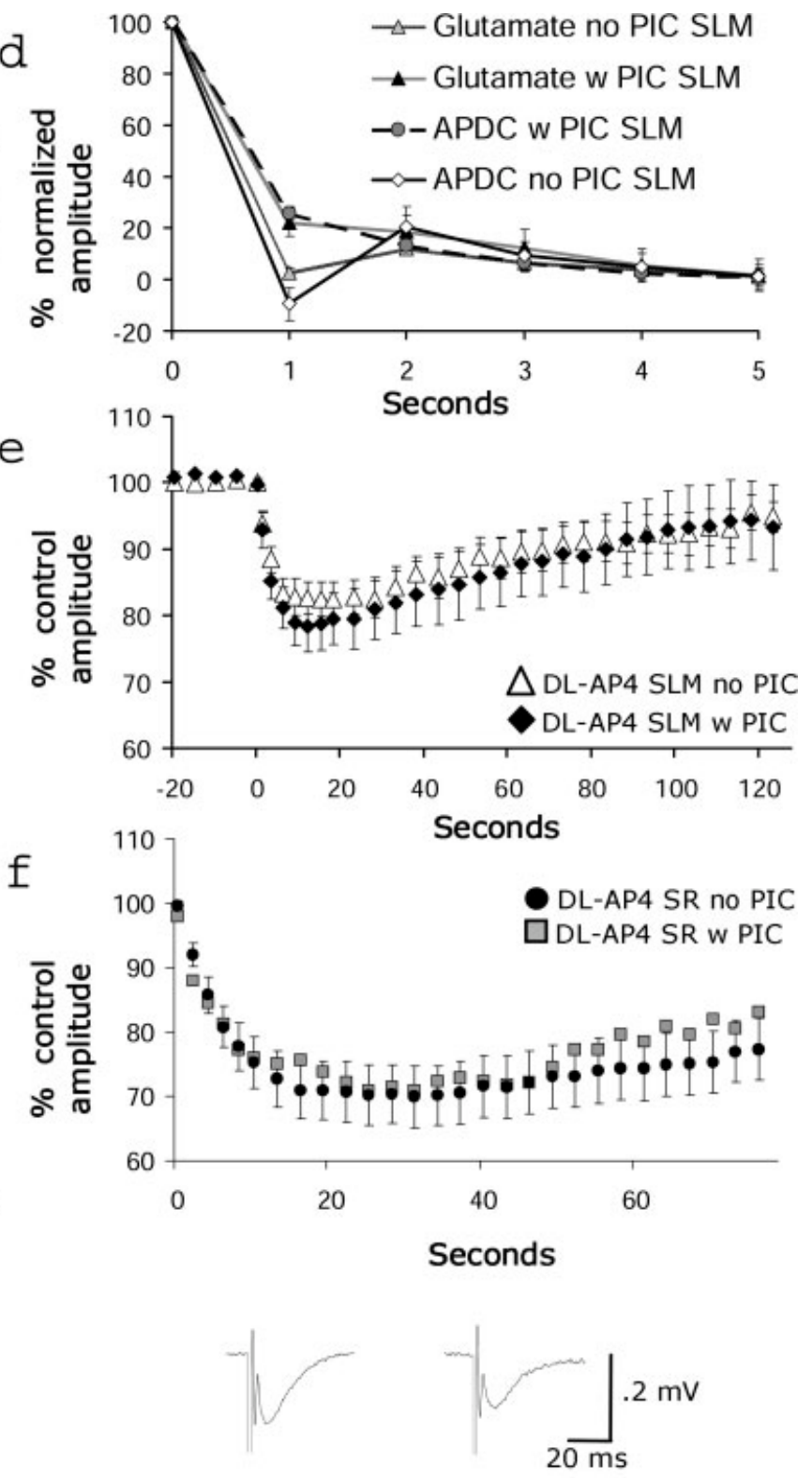

No picrotoxin

rotoxin in SLM after amplitude measurements were normalized to the maximum suppression value reached after the pulse of glutamate of $(2 R, 4 R)$-APDC. Each data point represents 5-11 data points from different experiments. In the absence of picrotoxin both glutamate and $(2 R, 4 R)-A P D C$ caused a transient biphasic change in synaptic transmission in SLM, then returned to the same time course of suppression as $(2 R, 4 R)-A P D C$ and glutamate in the presence of picrotoxin. (e) Time course of suppression by DL-AP4 in SLM in the presence $(n=9)$ and absence $(n=8)$ of picrotoxin. The onset of suppression was similar in SLM regardless of the picrotoxin condition. (f) Time course of suppression by DL-AP4 in SR in the presence $(n=7)$ and absence $(n=9)$ of picrotoxin. The onset of suppression was similar in SR regardless of the picrotoxin condition; however, in the absence of picrotoxin DL-AP4 caused slightly more suppression of synaptic transmission. (g) Examples of field potentials from experiments in Figure 5c. Left: Control field potential and field potential $100 \mathrm{~ms}$ after application of (2R,4R)-APDC glutamate in SLM in the presence of picrotoxin. Right: Control field potential and field potential $100 \mathrm{~ms}$ after application of $(2 R, 4 R)$ APDC in SLM in the absence of picrotoxin. 

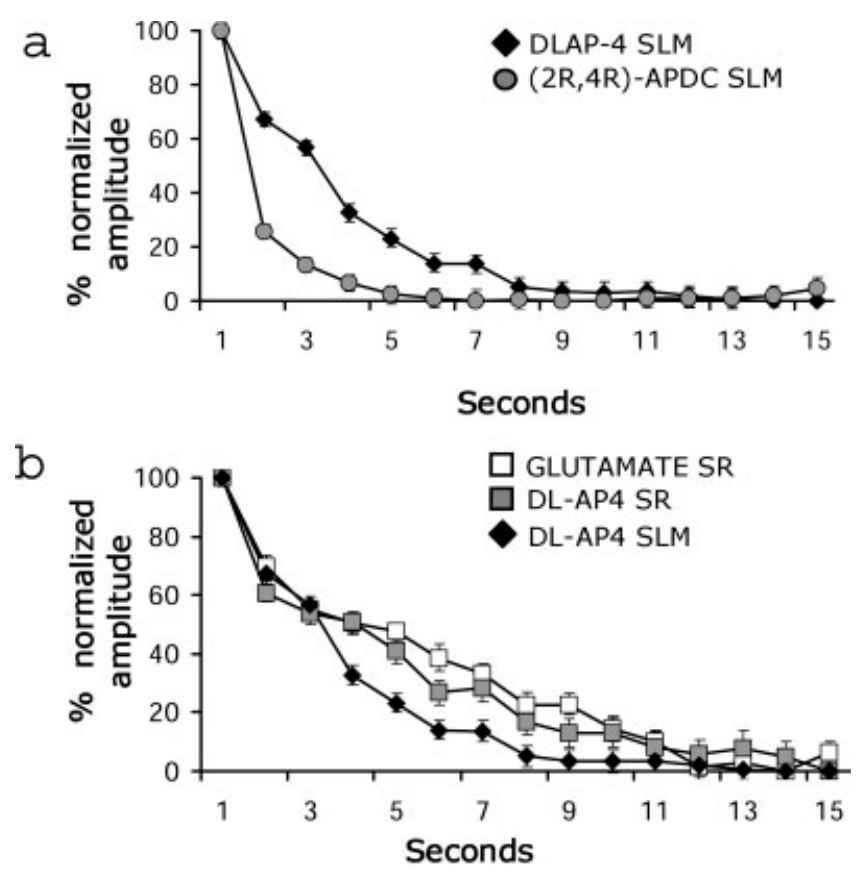

FIGURE 6. Comparisons of the effects of glutamate, (2R,4R)APDC $(n=9)$ and DL-AP4 $(n=8)$ in SLM and SR in the presence of picrotoxin. Evoked fEPSPs in all figures shown returned back to baseline; only the first part of the data is shown to highlight the difference in the onset time course. (a) Onset of suppression of synaptic transmission in SLM by DL-AP4 and (2R,4R)APDC after amplitude was normalized to the maximum suppression value reached. (b) Comparison of the onset of suppression for DL-AP4 in SLM $(n=9)$, DL-AP4 in SR $(n=7)$ and glutamate in SR $(n=5)$ after amplitude was normalized to the maximum suppression value reached. Although the onset for all drugs was similar, the onset of suppression was slightly faster for DL-AP4 in SLM when compared with DL-AP4 in SR and glutamate in SR.

that the time course of modulation by group III mGluRs is slightly lamina selective. Anatomical localization of group III mGluRs in the hippocampus has shown a higher density of the group III mGluR4 in SLM vs. SR of CA1 (Shigemoto et al., 1997; Corti et al., 2002) when compared with the group III mGluR7a, which is localized equally throughout both layers (Shigemoto et al., 1997). The laminar difference in the anatomical localization of mGluR4 could contribute to the pressure pulse application of DL-AP4, resulting in a faster onset of suppression in SLM when compared with that in SR.

\section{Mechanism of Onset of Suppression of Synaptic Transmission}

The similarity between the onset time constants for $(2 \mathrm{R}, 4 \mathrm{R})$ APDC and glutamate in SLM, and for DL-AP4 and glutamate in SR, suggests the difference in onset time constants is due to a difference between the two receptor groups, rather than to the chemical properties of the synthetic agonists. The endogenous agonist glutamate was applied in the same manner in both layers, but had clearly different onset time constants, suggesting this effect was not due to a difference in diffusion prop- erties of different agonists. The similarity between the onset time constant for glutamate in the absence and then presence of the group III agonist MSOP further supports this hypothesis. The overall consistency between different pharmacological manipulations suggests an intracellular difference between group II and group III mGluRs results in different time constants. Future work is needed to fully investigate the time course and effect of the intracellular signaling cascades affected by group II vs. group III mGluR activation.

The increase in paired pulse facilitation observed with the application of $(2 \mathrm{R}, 4 \mathrm{R})$-APDC in SLM suggests that presynaptic inhibition caused the onset of suppression observed. Application of $(2 R, 4 R)$-APDC caused the greatest amount of paired pulse facilitation during the onset of suppression of synaptic transmission, during which the difference between group II and group III effects was observed. After the onset of suppression, paired pulse facilitation decreased to smaller values but remained above baseline. The suppression by DL-AP4 in SLM was also accompanied by an increase in paired pulse facilitation but interestingly, although DL-AP4 caused suppression in SR, it caused little change in paired pulse facilitation (Fig. 4e) suggesting that the effect in SR may not be presynaptic. The very small increase in paired pulse facilitation is consistent with the small effect of DL-AP4 on facilitation in layer $1 \mathrm{~b}$ of piriform cortex (Hasselmo and Bower, 1991). This suggests that the reduction of synaptic potentials due to the application of DLAP4 in SR may have been due in part to postsynaptic depolarization. Alternatively, DL-AP4 could reduce synaptic potentials due to its proven capacity for acting as an antagonist at the NMDA receptor, assuming this class of receptor was present and active (Evans et al., 1982).

\section{$\mathrm{GABA}_{\mathrm{A}}$ Activation and Modulation by mGluRs}

Group II and group III mGluRs also modulate the release of GABA from interneurons in region CA1 of the hippocampus (Mitchell and Silver, 2000; Kogo et al., 2004; Price et al., 2005). The time course difference in suppression of synaptic transmission due to group II vs. group III mGluR activation did not change in the absence of picrotoxin; however, modulation of interneurons by mGluRs did play a role in the shape of the onset of suppression due to group II mGluR activation. In the absence of picrotoxin, application of $(2 \mathrm{R}, 4 \mathrm{R})-\mathrm{APDC}$ and $1 \mathrm{mM}$ glutamate in SLM resulted in a slightly faster onset time constant, most likely due to a rapid biphasic effect in SLM observed only in the absence of picrotoxin. The biphasic effect may have been due either to an initial suppression of glutamate and GABA release followed by a slight disinhibition of glutamatergic transmission due to the suppression of GABA release or, the transient depolarization of interneurons by mGluR activation, causing an initial and transient increase in the suppression of the fEPSPs.

In the absence of picrotoxin the onset time constant for the application of DL-AP4 in SLM was almost identical to the onset time constant, in the presence of picrotoxin, for DL-AP4 
TABLE 1.

Table for the Onset and Decay Time Constants for all Drugs Applied in all Conditions

\begin{tabular}{llrr}
\hline Location & \multicolumn{1}{c}{ Drug } & Onset(s) & Decay(s) \\
\hline SLM & Glutamate without picrotoxin & $0.2 \pm 0.5$ & $122.8 \pm 5.2$ \\
SLM & Glutamate with picrotoxin & $1.1 \pm 0.4$ & $95.88 \pm 1.7$ \\
SLM & (2R, 4R)-APDC (Group II agonist) without picrotoxin & $0.2 \pm 0.5$ & $182.1 \pm 6.8$ \\
SLM & (2R, 4R)-APDC (Group II agonist) with picrotoxin & $1 \pm 0.1$ & $134 \pm 1.9$ \\
SLM & DL-AP4 (Group III agonist) without picrotoxin & $4.1 \pm 0.3$ & $85.06 \pm 2.5$ \\
SLM & CDL-AP4 (Group III agonist) with picrotoxin & $3.8 \pm 0.2$ & $79.04 \pm 1.8$ \\
SLM & Glutamate in presence of MSOP (Group III antagonist) & $1.6 \pm 2.2$ & $179.6 \pm 4.4$ \\
SLM & Glutamate in presence of MSOP (Group III antagonist) & $0.3 \pm 0.2$ & $194.2 \pm 7.1$ \\
SR & Glutamate without picrotoxin & $10.9 \pm 0.7$ & $204.8 \pm 5.2$ \\
SR & Glutamate with picrotoxin & $4.4 \pm 0.8$ & $165 \pm 10.3$ \\
SR & DL-AP4 (Group III agonist) without picrotoxin & $12.3 \pm 0.9$ & $102 \pm 3.8$ \\
SR & DL-AP4 (Group III agonist) with picrotoxin & $7.8 \pm 1$ & $97.1 \pm 6.6$ \\
SR & Glutamate in absence of MSOP (Group III antagonist) & $6.9 \pm 0.2$ & $234.6 \pm 14$ \\
\hline
\end{tabular}

in SLM and $1 \mathrm{mM}$ glutamate in SR. In the absence of picrotoxin, pressure pulse application of DL-AP4 resulted in a faster onset of suppression in SLM when compared with that in SR in the absence of picrotoxin. Group III mGluRs have been shown to presynaptically inhibit interneuron EPSCs in the perforant path (Price et al., 2005). The differences in the time courses of DL-AP4 in SR and SLM and the influence of the presence of picrotoxin on these differences highlights the fact that group III mGluRs most likely have complex effects at GABAergic and glutamatergic terminals. Future experiments should investigate the differences in the time course of group III mGluR modulation on synaptic transmission at GABAergic vs. glutamatergic synapses. Table 1 lists all of the onset and decay time constants for the application of various drugs in SLM and SR.

\section{Functional Significance}

Activation of group II mGluRs have been associated with anxiolytic (Pilc et al., 2000; Linden et al., 2004) and analgesic behavioral effects (Jones et al., 2005). In vitro work has shown that activation of group II mGluRs in SLM of the hippocampus presynaptically inhibits the release of glutamate (Gereau and Conn, 1995; Kew et al., 2001). The fast onset time course of group II mGluR modulation of synaptic transmission could allow group II mGluRs to underlie a rapidly activating low pass filter for strong, incoming input. In the hippocampus, high frequency stimulation has been shown to activate group II mGluRs whereas low frequency stimulation did not result in the activation of group II mGluRs (Scanziani et al., 1997). In addition, anatomical localization of group II mGluRs as distal from the active zone (Shigemoto et al., 1997) suggests that activity would have to reach a high threshold to activate the fast suppression of glutamatergic synaptic transmission by group II mGluRs. This could allow group II mGluRs to selectively filter out only stimuli that were persistent, very strong or repetitive and may help explain the anxiolytic, analgesic and habituating behavioral effects of group II mGluR activation. The fast onset of suppression of synaptic transmission by group II mGluRs could also provide a neuroprotective effect against epileptic and seizure-like activity. Group II mGluRs have been shown to have neuroprotective and antiepileptic effects (Klondzinska et al., 2000; Flor et al., 2002; Folbergrova et al., 2005). If glutamate levels reached a dangerously high level, group II mGluRs could quickly suppress glutamatergic synaptic transmission. In addition, suppression of glutamatergic synaptic transmission by group II mGluRs in the perforant path could complement nicotinic enhancement of glutamatergic synaptic transmission in the same pathway (Giocomo and Hasselmo, 2005).

The suppression of synaptic transmission due to group II mGluR activation is fast enough to fit within the falling phase of the theta rhythm. Activation of group II mGluRs could reduce the subsequent influence of incoming entorhinal input, allowing more separation between similar incoming patterns of activity in the hippocampus. The dynamics of group II mGluR modulation of activity in SLM suggests that presynaptic inhibition via group II mGluRs could provide one component of the phasic change in current sink in SLM during theta rhythm (Brankack et al., 1993). Activation of group II mGluRs has also been shown to cause bursts in CA3 of the hippocampus (Cobb et al., 2000). The biphasic effect observed in SLM with $(2 \mathrm{R}, 4 \mathrm{R})-\mathrm{APDC}$ in the absence of picrotoxin indicates that group II mGluRs modulate interneuron activity in SLM. The modulation of interneurons by group II mGluRs may contribute to the burst activity observed as the result of group II mGluR activation in CA3.

Group III mGluRs have also been shown to reduce anxiety and have antidepressant like behavioral effects (Linden et al., 2002; Tatarczynska et al., 2002; Bergink et al., 2004). In addition, agonists for presynaptic group II and group III mGluRs have been shown to facilitate olfactory learning while blockade of mGluRs in the olfactory cortex of awake, behaving rats 
diminishes habituation of a simple odor, supporting the hypothesis that mGluRs play a key role in odor discrimination, habituation, and cortical adaptation (Best and Wilson, 2004; Best et al., 2005). The slower onset time course of suppression of synaptic transmission indicates that group III mGluRs also function as neuromodulators of glutamatergic synaptic transmission. The difference in the time course of group III modulation of synaptic transmission suggests that group III mGluRs could also contribute as a high pass filter in the Schaffer collaterals, complementing the fast suppression of synaptic transmission by group II mGluRs. In SLM, group III mGluRs could complement the role of group II mGluRs, providing additional suppression of glutamatergic synaptic transmission in response to repetitive stimulation.

\section{Acknowledgments}

Thanks to Eric Zilli for his comments on early drafts of the paper.

\section{REFERENCES}

Bergink V, Van Megen HJGM, Westenberg HGM. 2004. Glutamate and anxiety. Eur Neuropsychopharmacol 14:175-183.

Best AR, Wilson DA. 2004. Coordinate synaptic mechanisms contributing to olfactory cortical adaptation. J Neurosci 24:652-660.

Best AR, Thompson JV, Flietcher ML, Wilson DA. 2005. Cortical metabotropic glutamate receptors contribute to habituation of a simple odor evoked behavior. J Neurosci 25:2513-2517.

Brankack J, Stewart M, Fox SE. 1993. Current source density analysis of the hippocampal theta rhythm: Associated sustained potentials and candidate synaptic generators. Brain Res 615:310-327.

Capogna M. 2004. Distinct properties of presynaptic group II, III metabotropic glutamate receptor-mediated inhibition of perforant pathway-CA1 EPSCs. Eur J Neurosci 19:2847-2858.

Cobb SR, Bulters DO, Davies CH. 2000. Coincident activation of mGluRs and mAChRs imposes theta frequency patterning on synchronised activity in the hippocampal CA3 region. Neuropharmacology 39:1933-1942.

Conn PJ, Pin JP. 1997. Pharmacology and functions of metabotropic glutamate receptors. Ann Rev Pharmacol Toxicol 37:205-237.

Corti C, Aldegheri L, Somogyi P, Ferriguti F. 2002. Distribution and synaptic localization of the metabotropic glutamate receptor 4 (mGluR4) in the rodent CNS. Neuroscience 110:403-420.

Dietrich D, Beck H, Kral T, Clusmann H, Elger CE, Schramm J. 1997. Metabotropic glutamate receptors modulate synaptic transmission in the perforant path: Pharmacology and localization of two distinct receptors. Brain Res 767:220-227.

Evans RH, Francis AA, Jones AW, Smith DA, Watkins JC. 1982. The effects of a series of $\omega$-phosphonic $\alpha$-carboxylic amino acids on electrically evoked and excitant amino acid-induced responses in isolated spinal cord preparations. Br J Pharmacol 75:65-75.

Flor PJ, Battaglia G, Nicoletti F, Gasparini F, Bruno V. 2002. Neuroprotective activity of metabotropic glutamate receptor ligands. Adv Exp Med Biol 513:197-223.

Folbergrova J, Druga R, Otahal J, Haugvicova R, Mares P, Kubova H. 2005. Seizures induced in immature rats by homocysteic acid and the associated brain damage are prevented by group II metabotropic glutamate receptor agonist $(2 \mathrm{R}, 4 \mathrm{R})$-4-aminopyrrolidine-2,4dicarboxylate. Exp Neurol 192:420-436.
Gereau RW, Conn PJ. 1995. Multiple presynaptic metabotropic glutamate receptors modulate excitatory and inhibitory synaptic transmission in hippocampal area CA1. J Neurosci 15:6879-6889.

Giocomo LM, Hasselmo M. 2005. Nicotinic modulation of glutamatergic synaptic transmission in region CA3 of the hippocampus. Eur J Neurosci 22:1349-1356.

Hasselmo ME, Bower JM. 1991. Selective suppression of afferent but not intrinsic fiber synaptic transmission by 2-amino-4-phophonobutyric acid (AP4) in piriform cortex. Brain Res 548:248-255.

Hasselmo ME, Fehlau BP. 2001. Differences in time course of ACh and GABA modulation of excitatory synaptic potentials in slices of rat hippocampus. J Neurophysiol 86:1792-1802.

Jane D, Doherty A. 2000. Muddling through the mGlu maze? Tocris Rev13.

Jones CK, Eberle EL, Peters SC, Monn JA, Shannon HE. 2005. Analgesic effects of the selective group II (mGlu2/3) metabotropic glutamate receptors agonists LY379268 and LY389795 in persistent and inflammatory pain models after acute and repeated dosing. Neuropharmacology 49(Suppl 1):206-218.

Kew JNC, Ducarre JM, Pfimlin MC, Mutel V, Kemp JA. 2001. Activity-dependent presynaptic autoinhibition by group II metabotropic glutamate receptors at the perforant path inputs to the dentate gyrus and CA1. Neuropharmacology 40:20-27.

Klondzinska A, Bijak M, Chojnacka-Wojcik E, Kroczka B, Swaider M, Czuczwar SJ, Pilc A. 2000. Roles of group II metabotropic glutamate receptors in modulation of seizure activity. Naunyn Schmiedebergs Arch Pharmacol 361:283-288.

Koerner JF, Cotman CW. 1981. Micromolar L-2-amino-4-phosphonobutyric acid selectively inhibits perforant path synapses from lateral entorhinal cortex. Brain Res 216:192-198.

Kogo N, Dalezios Y, Capogna M, Ferriguti F, Shigemoto R, Somogyi P. 2004. Depression of GABAergic input to identified hippocampal neurons by group III metabotropic glutamate receptors in the rat. Eur J Neurosci 19:2727-2740.

Linden AM, Johnson BG, Peters SC, Shannon HE, Tian M, Wang Y, Yu JL, Koster A, Baez M, Schoepp DD. 2002. Increased anxietyrelated behavior in mice deficient for metabotropic glutamate 8 (mGluR8) receptor. Neuropharmacology 43:251-259.

Linden AM, Greene SJ, Bergeron M, Schoepp DD. 2004. Anxiolytic activity of the MGLU2/3 receptor agonist LY354740 on the elevated plus maze is associated with the suppression of stress-induced c-Fos in the hippocampus and increases in c-Fos induction in several other stresssensitive brain regions. Neuropsychopharmacology 29: 502-513.

Manzoni OJ, Castillo PE, Nicoll RA. 1995. Pharmacology of metabotropic glutamate receptors at the mossy fiber synapses of the guinea pig hippocampus. Neuropharmacology 34:965-971.

Mitchell SJ, Silver RA. 2000. Glutamate spillover suppresses inhibition by activating presynaptic mGluRs. Nature 404:498-502.

Mott DD, Lewis DV. 1991. Facilitation of the induction of long-term potentiation by GABAB receptors. Science 252:1718-1720.

Otis TS, De Koninck Y, Mody I. 1993. Characterization of synaptically elicited GABAB responses using patch-clamp recordings in rat hippocampal slices. J Physiol 463:391-407.

Pilc A, Chojnacka-Wojcik E, Tatarczynska E, Borycz J, Kroczka B. 2000. Stimulation of group II metabotropic glutamate receptors or inhibition of group I exerts anxiolytic-like effects in rats. Amino Acids 19:81-86.

Price CJ, Karayannis T, Pal BZ, Capogna M. 2005. Group II, III mGluRs-mediated presynaptic inhibition of EPSCs recorded from hippocampal interneurons of CA1 stratum lacunosum moleculare. Neuropharmacology 49:45-56.

Scanziani M, Salin PA, Vogt KE, Malenka RC, Nicoll RA. 1997. Usedependent increases in glutamate concentration activate presynaptic metabotropic glutamate receptors. Nature 385:630-634.

Shigemoto R, Kinoshita A, Wada E, Nomura S, Ohishi H, Takada M, Flor PJ, Neki A, Abe T, Nakanishi S, Mizuno N. 1997. Differential presynaptic localization of metabotropic glutamate receptor subtypes in the rat hippocampus. J Neurosci 17:7503-7522. 
Shoepp DD. 2001. Unveiling the functions of presynaptic metabotropic glutamate receptors in the central nervous system. J Pharmacol Exp Ther 299:12-20.

Shoepp DD, Jane DE, Monn JA. 1999. Pharmacological agents acting as subtypes of metabotropic glutamate receptors. Neuropharmacology 38:1431-1476.

Solis JM, Nicoll RA. 1992. Pharmacological characterization of GABAB mediated responses in the CA1 region of the rat hippocampal slice. J Neurosci 12:3466-3472.

Tatarczynska E, Palucha A, Szewczyk B, Chojnacka-Wojcik E, Wieronska J, Pilc A. 2002. Anxiolytic and antidepressant like effects of group III metabotropic glutamate agonist (1S,3R,4S)-1-aminocyclopentane-1,3,4-tricarboxylic acid (ACPT-I) in rats. Pol J Pharmacol 54:707-710.

Vignes M, Clarke VR, Davies CH, Chambers A, Jane DE, Watkins JC, Collingridge GL. 1995. Pharmacological evidence for an involvement of group II, group III mGluRs in the presynaptic regulation of excitatory synaptic responses in the CA1 region of rat hippocampal slices. Neuropharmacology 34:973-982.

Wilson MA, Bower JM. 1992. Cortical oscillations and temporal interactions in a computer simulation of piriform cortex. J Neurophysiol 67:981-995. 